\title{
Massive Hemorrhage into Intracranial Neurinomas
}

\author{
Mark G. Goetting, M.D., and Steven E. Swanson, M.D. \\ Departments of Pediatrics, Neurology, and Surgery, University of Michigan Medical Center, Ann Arbor, Michigan
}

Goetting MG, Swanson SE. Massive hemorrhage into intracranial neurinomas. Surg Neurol 1987:27:168-72.

\begin{abstract}
Massive bleeding into an intracranial neurinoma is a rare event. The 12th case of this particular occurrence, which was precipitated by weight lifting, is described and a review of the literature is presented. Risk factors for bleeding appear to be tumor size and vascularity. Presenting symptomatology is abrupt and includes headache, nausea, vomiting, and depressed consciousness. Preexisting symptoms referrable to and marked dysfunction of the cranial nerve of origin are present. Deficits of neighboring cranial nerves are frequent. Computed tomography demonstrates the hemorrhages and the tumors. Mild head injury and physical exertion were precipitating factors in two cases. One-fourth of the patients died, while the others made good recoveries.
\end{abstract}

KEY WORDS: Hemorrhage; Neurinoma

Intracranial neurinomas are common tumors whose symptoms are caused by compression of the cranial nerve of origin or adjacent tissue. Massive hemorrhage is a distinctly rare event. Such a case is presented here, where massive hemorrhage occurred while weight lifting. Previous cases are summarized and the pathogenesis of hemorrhage is discussed. Risk factors for major bleeding and clinical features suggesting the diagnosis are presented.

\section{Case Report}

A 19-year-old man presented to the emergency department with acute left-sided otalgia and facial weakness. While performing the ninth lift in a set of heavy weight lifting exercises he experienced intense left-sided deep otalgia. The pain slowly increased in severity. Two and a half hours later, the left side of his face became weak and he developed vertigo, sweating, and vomiting. He improved over the next 45 minutes, and was left

Address reprint requests to: Dr. Mark Goetting, Division of Pediatric Intensive Care, I-3, 2799 West Grand Boulevard, Detroit, MI 48202. with mild otalgia, facial paralysis, and partial hearing loss, all left-sided. One month earlier he had taken decongestants for hearing impairment and intermittent tinnitus of the same side. He felt he had been improving. During the 2 weeks prior to admission he had experienced occasional mild bifrontal headaches. There was no history of trauma or family history of neurocutaneous disease.

Physical examination revealed a muscular young man in no distress. He was afebrile and normotensive. Flexion of his neck caused minimal posterior cervical discomfort bilaterally. There was no craniocervical tenderness or bruit. Tympanic membranes appeared normal. No cafe-au-lait spots or neurofibromas were detected.

The patient was mildly lethargic. Ocular fundi and pupillary responses were normal. He had gaze-evoked, right-sided horizontal nystagmus without a rotatory component. There was marked left facial paresis. Taste perception was absent on the left side. The Weber test lateralized to the right. Air conduction exceeded bone conduction bilaterally with a moderate hearing loss on the left. Cold caloric testing showed minimal left-sided response. The other cranial nerves were intact. Motor and sensory examinations were unremarkable. Deep tendon reflexes were physiologic with downgoing toes to plantar stimulation. Tandem gait was slightly ataxic. Coordination was otherwise normal.

Hemogram, routine chemistries, and coagulation studies were normal. A computed tomography (CT) scan of the brain demonstrated a spherical high-density lesion with an intrinsic area of higher density at the left cerebellopontine angle (Figure 1). Contrast medium produced a homogeneous density throughout the mass. The internal auditory canal was enlarged. Four-vessel angiography was normal. Magnetic resonance imaging (MRI) added no new information.

Suboccipital craniectomy revealed a fresh clot protruding from a $3.2-\mathrm{cm}$ acoustic neurinoma. A small amount of subarachnoid blood was present. The majority of the tumor was removed uneventfully and the facial nerve was preserved. The remainder was inaccessible within the auditory canal and necessitated a translabyrinthine approach in a second procedure.

Microscopy showed a mixture of typical Antoni A 


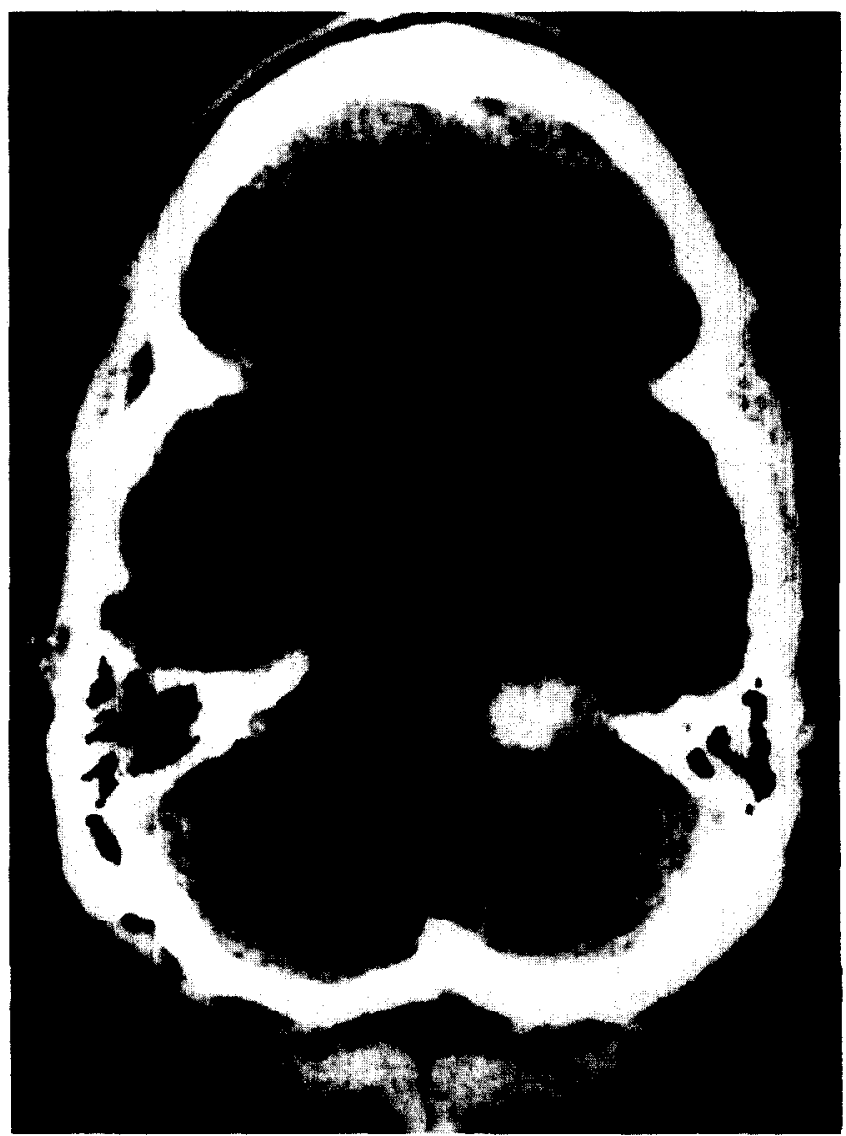

A

and $\mathrm{B}$ patterns. There were several areas of hypervascularity characterized by numerous thin-walled, dilated vessels in clusters (Figure 2). Many of these were near the surface. Areas of microscopic hemorrhage abutted some of these.

Two months later the patient resumed his former activities. Left facial weakness and hearing loss are the only remaining deficits.

\section{Discussion}

Hemorrhage into brain tumors is common. One to $11 \%$ of all intracranial bleeding originates from brain tumors and serious bleeding complicates up to $10 \%$ of tumors $[3,5,7,12,16,18,20]$. Neoplasms that are more prone to significant hemorrhage include malignant glioma, meningioma, melanoma, choriocarcinoma, pituitary adenoma, oligodendroglioma, and choroid plexus papilloma [23]. Neurinomas account for approximately $8 \%$ of all brain tumors [19]. Despite this high prevalence, massive hemorrhage is a rare event with these tumors. The present case is the 12 th reported occurrence (Table 1 ).

Analysis of reported cases reveals that all hemorrhages occurred in large neurinomas $(>2 \mathrm{~cm})$. Second-

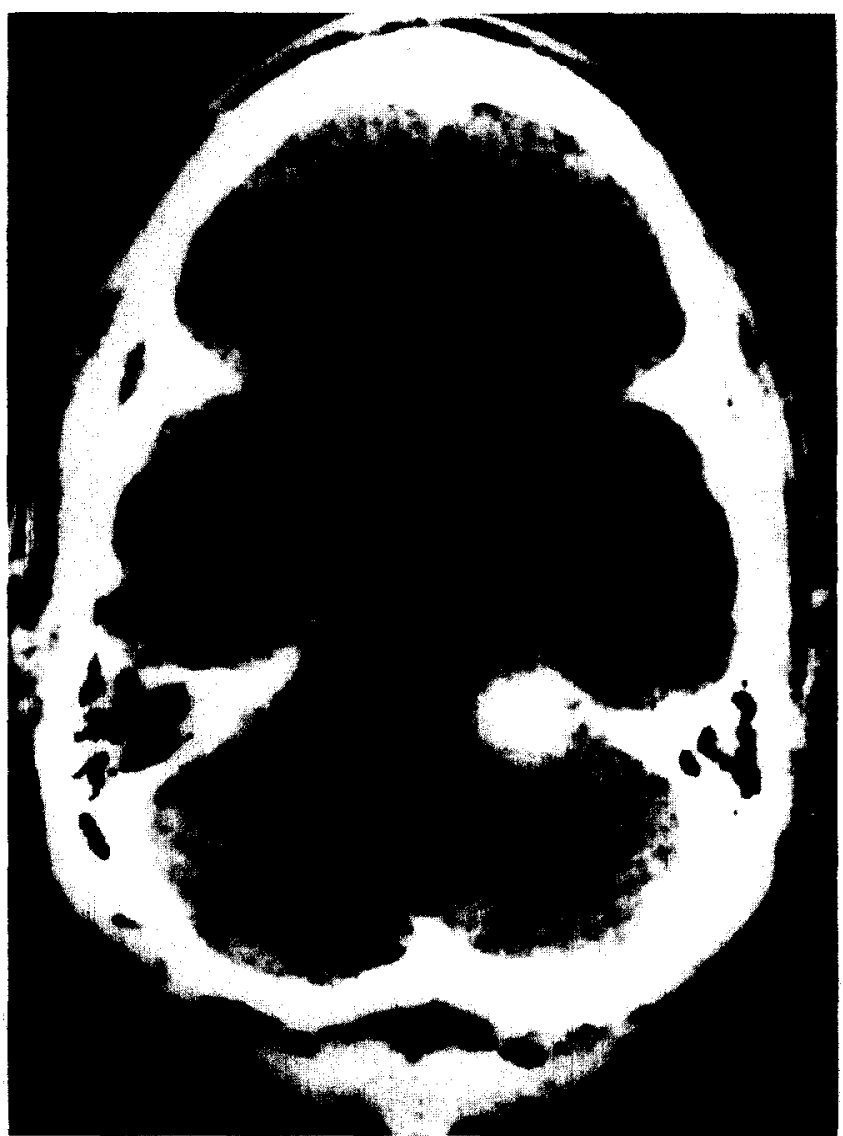

B

Figure 1. Computed tomographic scan without contrast enhancement (A) and with contrast enbancement (B) performed bours after hemorrbage. Note the clot demonstrated on the scan uithout enbancement.

ary effects of hematoma formation and edema cannot account for their size. This is remarkable, as one-third to one-half of symptomatic tumors are smaller and certainly many other small tumors remain undiagnosed [8,9]. Although size appears to be an important risk factor for major bleeding, it seems that the association relates to intrinsic tumor vascularity and not to extrinsic vessel crosion, compression, or aneurysm formation. All cases underwent angiographic, operative, or pathologic visualization, with no suggestion of these.

Hypervascularity is a common finding in neurinomas. Almost $60 \%$ of tumors larger than $2 \mathrm{~cm}$ in size have a marked increase in vascularity, whereas only $20 \%-25 \%$ of the smaller tumors have a marked increase in vascularity (9). Vessels are often dilated, ectatic, and thinwalled, frequently lined by only a single layer of endothelium. In large tumors the degree of vascularity can be so pronounced as to warrant categorization as hemangioma [10]. Also stromal support, as indexed by tumor cellularity and collagenization, is weaker in large 


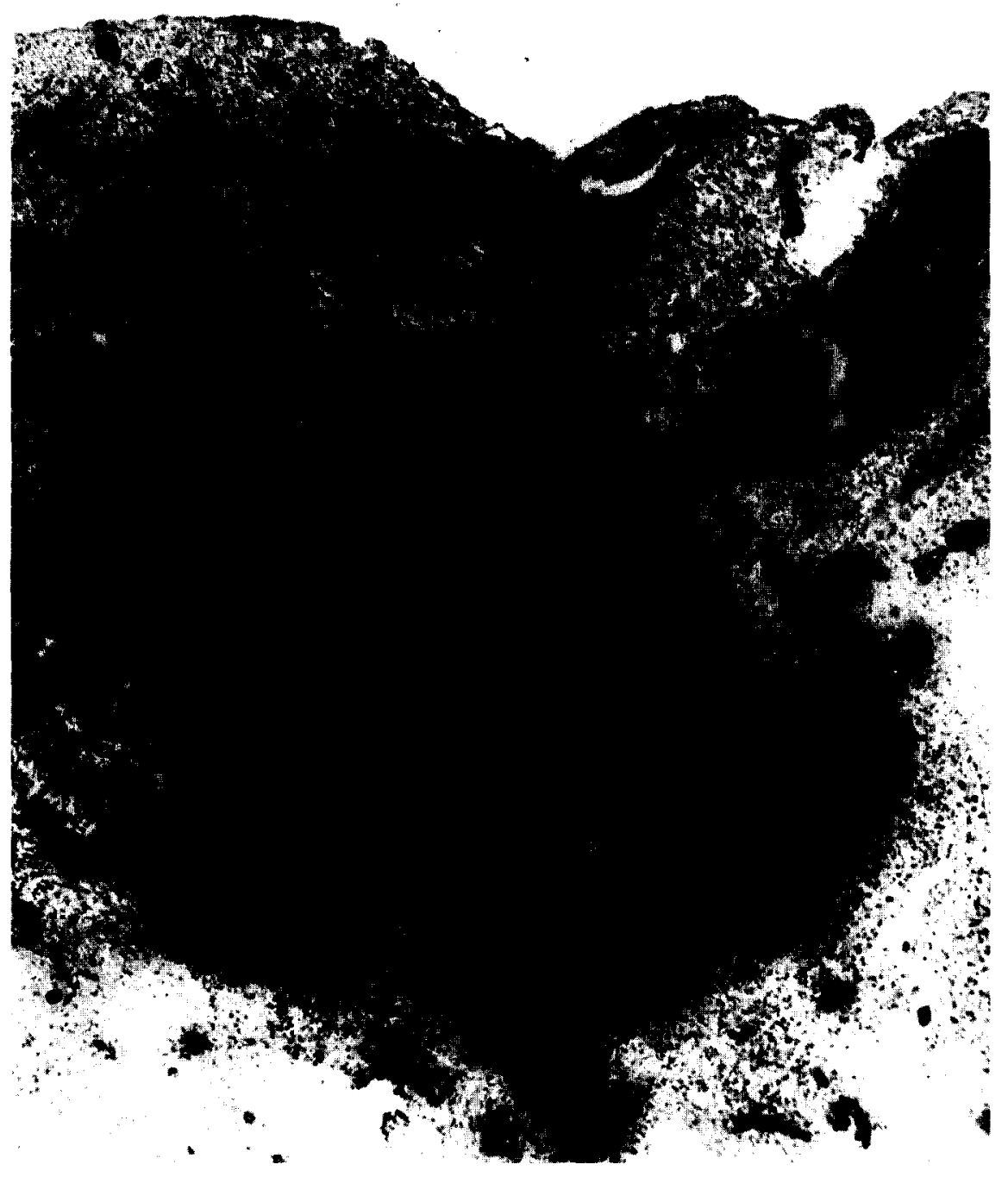

neurinomas [9]. All of these factors presumably predispose to hemorrhage. Indeed microscopic bleeding is common in these tumors. Tissue hemosiderin-laden macrophages and cerebrospinal fluid xanthochromia are frequently encountered, especially with the larger specimens [14,19].

Pathologic descriptions of 7 of the 12 cases include dilated vessels, increased vascularity, or a hemangioma. An additional report (case 4) describes increased vascularity noted during operation. Details of the histology were usually absent from the reports.

While tumor size can be measured radiographically, no reliable indirect assessment of vascularity is known. Magnetic resonance imaging scans and contrast enhanced CT scans have not yet been studied in this regard. Cerebral angiography uncommonly demonstrates tumor staining in neurinomas, but often shows displacement of major vessels in the posterior fossa [17]. All patients underwent angiography, except for cases 1 and
Figure 2. Numerous thin-walled, dilated vessels at the periphery of the tumor. An adjacent bemorrbage is apparent (bematoxylin and eosin, $\times 40 \%$.

11. Mass effect without tumor blush was described in each patient, except for cases 4 and 12 who had normal four-vessel studies. Selective external injections into the carotid artery have recently been shown to produce tumor staining in half of the acoustic neurinomas [17]. This technique holds the most promise for radiological grading of vascularity but requires pathologic correlation.

At least 9 of 12 patients had prodromal symptomatology ranging from 5 days to 7 years or more. It is uncertain if preexisting deficits had been present in the others. Symptoms were typical of cerebellopontine angle neoplasms. All eighth nerve lesions caused hearing disturbances, while the two fifth nerve masses produced facial numbness.

Precipitating factors have been described previously 
Table 1. Summary of Cases from the Literature

\begin{tabular}{|c|c|c|c|c|c|c|c|c|}
\hline $\begin{array}{l}\text { Case } \\
\text { no. }\end{array}$ & Aurhors & $\begin{array}{l}\text { Age } \\
(\mathrm{yr})\end{array}$ & Sex & Prodrome & $\begin{array}{c}\text { Location } \\
\text { (cranial } \\
\text { nerve) }\end{array}$ & $\begin{array}{l}\text { Size } \\
(\mathrm{cm})\end{array}$ & Vascularity & Outcome \\
\hline 1 & Baba et al (1) & 71 & $\mathrm{~F}$ & Several years & 8 & $>2$ & $\begin{array}{l}\text { Numerous dilated } \\
\text { vessels }\end{array}$ & Deuch \\
\hline 2 & Castillo et al (2) & 61 & M & 2 years & 8 & 3 & $\begin{array}{l}\text { Numerous dilaced } \\
\text { vessels }\end{array}$ & Good $d^{b}$ \\
\hline 3 & Fine et al (4) & 21 & $\mathrm{~F}$ & 5 days & 8 & $>2$ & Not described & Good \\
\hline 4 & Glecson et al (6) & 54 & $\mathrm{~F}$ & Several years & 8 & $4 \times 4 \times 4$ & Not described & Good \\
\hline 5 & $\begin{array}{l}\text { Kasantikul \& } \\
\text { Netsky (10) }\end{array}$ & 64 & $\mathbf{M}$ & Unknown & 8 & $2^{\prime \prime}$ & $\begin{array}{l}\text { Cavernous } \\
\text { angioma }\end{array}$ & Death \\
\hline 6 & Kubota et al (11) & 43 & $\mathbf{M}$ & 2 months & 5 & 3 & $\begin{array}{l}\text { Numerous dilated } \\
\text { vessels }\end{array}$ & Good \\
\hline 7 & McKoyd et al (13) & 64 & $\mathrm{~F}$ & Unknown & 8 & $2 \times 3 \times 3.5$ & $\begin{array}{l}\text { Numerous dilated } \\
\text { vessels }\end{array}$ & Death \\
\hline 8 & $\begin{array}{l}\text { Shephard \& Cheeks } \\
\text { (21) }\end{array}$ & 37 & $\mathbf{M}$ & Unknown & 8 & "Large" & Increased & Good \\
\hline 9 & $\begin{array}{l}\text { Shephard \& Cheeks } \\
\text { (21) }\end{array}$ & 66 & M & $>10$ months & 8 & 3 & Not described & Good \\
\hline 10 & $\begin{array}{l}\text { Shimabukuro } \\
\text { et al (22) }\end{array}$ & 33 & $\mathrm{M}$ & 1 month & 5 & $5.8 \times 3.5$ & $\begin{array}{l}\text { Numerous dilated } \\
\text { vessels }\end{array}$ & Good \\
\hline 11 & Yonemitsu et al (23) & 49) & $\mathbf{M}$ & 7 years & 8 & $5 \times 5 \times 4$ & $\begin{array}{l}\text { Thin-walled } \\
\text { dilated vesseis }\end{array}$ & Good \\
\hline 12 & Present case & 19 & M & 1 month & 8 & 3.2 & $\begin{array}{l}\text { Numerous thin- } \\
\text { walled, dilated } \\
\text { vessels }\end{array}$ & Good \\
\hline
\end{tabular}

Presumably $>2 \mathrm{~cm}$

"Castillo R, Netsky M (personal communications).

in two parients. Case 9 involved hemorrhage into a trigeminal neurinoma draped over the tentorium presenting the day after a minor head injury. The authors speculate that contusion of the tumor occurred with resultant mass effect. Our patient was in the midst of heavy weight lifting. We suggest that the abrupt and marked increase in arterial and venous pressures created a brief gradient between the vascular and extravascular intracranial compartments, leading to rupture of fragile tumor vessels. Two other patients were sleeping at the presumed time of their hemorrhage. Other reports in the literature did not comment on precipitating factors.

Subarachnoid hemorrhage occurred in 10 cases while bleeding was restricted to the tumor in the others. Presenting features were variable. Headache, nausea, vomiting, and altcred consciousncss werc common. In all patients tested there was marked dysfunction of the cranial nerve of origin. New deficits of neighboring cranial nerves were common. Impaired consciousness prevented assessment in two cases, and data on case 11 are missing. Computed tomography scans demonstrated the tumor in all seven cases where performed.

Tumor excision was accomplished in 10 patients. One patient (case 8) died in the postoperative period. Two patients died without operation. The nine survivors recovered with a good outcome, generally with only cra- nial nerve deficits. All were able to return to their former activities.

Awareness that catastrophic bleeding can complicate intracranial neurinomas should not affect the decision of whether to remove such a tumor. Large tumors should be removed and small tumors are at lower risk for hemorrhage. One could argue that an incidental neurinoma is a relative contraindication to anticoagulation, as this has induced massive hemorrhage in a spinal neurinoma [15].

Finally, one should add intracranial neurinoma to the list of causes of angiogram-negative subarachnoid hemorrhage. Computed tomography scans are a sensitive but not infallible tool for diagnosing neurinomas [8]. Questioning the patient for preexisting symptomatology and a detailed cranial nerve examination will adequately screen these cases.

The author thanks Dr. Julian Hoff for his suggestions and encouragement. Mrs. Joyce London provided secretarial suppurt.

\section{References}

1. Baba M, Iseki H, Kumagai Y, Sugiyama H, Nawada H. Acoustic neurinoma with massive hemorrhage within the tumor tissue. No Shinkei Geka 1980;8:193-7. 
2. Castillo $R$, Watts $C$, Pulliam $M$. Sudden hemorrhage in an acoustic neuroma. J Neurosurg 1982;56:417-9.

3. Cook AW, Plaut M, Browder J. Spontaneous intracerebral hemorrhage: factors related to surgical results. Arch Neurol 1965;13:25-9.

4. Fine R, Williams B, Dowling J. Acoustic neuroma causing subarachnoid haemorrhage. Med J Aust 1977;1:37-9.

5. Glass B, Abbotr KH. Subarachnoid hemorrhage consequent to intracranial tumors. Arch Neurol Psychiatry 1955;73:369-79.

6. Gleeson RK, Butzer JF, Grin OD. Acoustic neurinoma presenting as subarachnoid hemorrhage. J Neurosurg 1978;49:602-4.

7. Globus JH, Sapirstein M. Massive hemorrhage into brain tumor. JAMA 1942;120:348-52.

8. Harner SG, Laws ER Jr. Clinical findings in patients with acoustic neurinoma. Mayo Clin Proc 1983;58:721-8.

9. Kasantikul V, Netsky MG, Glasscock ME, Hays JW. Acoustic neurilemmoma: clinicoanatomical study of 103 patients. J Neurosurg 1980;52:28 35 .

10. Kasantikul V, Netsky M. Combined neurilemmoma and angioma. J Neurosurg 1979;50:81-7.

11. Kubota T, Hayashi M, Yamamoto S. Subarachnoid hemorrhage due to trigeminal neurinoma. Surg Neurol 1981;16:157-60.

12. Locksley HB, Sahs AL, Sandler R. Report on the cooperative study of intracranial aneurysm and subarachnoid hemorrhage. Section 3. Subarachnoid hemorrhage unrelated to intracranial aneurysm and A-V malformation. A study of associated diseases and prognosis. J Neurosurg 1966;24:1034-56.
13. McKoyd K, Barron KD, Cassidy RJ. Acoustic neurinoma presenting as subarachnoid hemorrhage. J Neurosurg 1974;41:391-3.

14. Merritt HH. Cerebrospinal fluid in cases of tumors of the brain. Arch Neurol Psychiatry 1935;34:1175-87.

15. Motomochi M, Makita Y, Nabeshima S, Iragaki T, Tci T. Spinal subarachnoid hemorrhage due to thoracic neurinoma during anticoagulation therapy. Neurol Med Chir (Tokyo) 1981;21:781-4.

16. Padt JP, Renck JD, Eecken H. Intracerebral hemorrhage as initial symptom of a brain tumor. Acta Neurol Belg 1973;73:241-51.

17. Perneczky A. Blood supply of acoustic neurinomas. Acta Neurochir 1980;52:209-18.

18. Russell DS. The pathology of spontaneous intracranial hemorrhage. Proc Soc Med 1954;47:689-93.

19. Russell DS, Rubenstein LJ. Pathology of tumors of the nervous system. Baltimore, MD: Williams and Wilkins, 1977;372-401.

20. Scott M. Spontaneous intracerebral hematoma caused by cerebral neoplasms. J Neurosurg 1975;42:338-42.

21. Shephard RH, Cheeks RE. Subarachnoid haemorrhage and acoustic neuroma. J Neurol Neurosurg Psychiatry 1981;44:1057.

22. Shimabukuro H, Masuzawa T, Miyagi K, Sato F. Trigeminal neurinoma revealed by intratumoral hemorrhage following a minor head injury. Surg Neurol 1983;19:346-50.

23. Yonemitsu T, Niizuma H, Kodama N, Fujiwara S, Suzuki J. Acoustic neurinoma presenting as subarachnoid hemorrhage. Surg Neurol $1983 ; 20: 125-130$ 